\title{
Analisis Penugasan Guna Meminimumkan Waktu Pengiriman Produk Menggunakan Metode Hungarian pada UKM Roti ZB Cikampek
}

\author{
Yasir Arafat $^{1)}$ dan Agustian Suseno ${ }^{2)}$ \\ Jurusan Teknik Industri, Fakultas Teknik, Universitas Singaperbangsa Karawang, Jl. HS. Ronggo Waluyo, \\ Telukjambe Timur Karawang Jawa Barat 41361, Indonesia \\ 1) $1710631140179 @$ student.unsika.ac.id \\ 2) agustian.suseno@ft.unsika.ac.id
}

\begin{abstract}
Abstrak. UKM (Usaha Kecil Menengah) Roti ZB adalah perusahaan yang bergerak pada bidang makanan. Permasalahan yang sedang dihadapi oleh perusahaan yakni penugasan pengiriman produk kepada konsumen, masing-masing karyawan difasilitasi alat transportasi yang sama tetapi mempunyai waktu pengantaran yang berbeda. Tujuan dari penelitian ini adalah mengetahui efesiensi waktu pengiriman yang dihasilkan dengan memakai metode Hungarian, serta memberikan penyelesaian pengaturan penempatan karyawan dalam pengantaran produk kepada konsumen berdasarkan metode Hungarian. Penelitian ini menggunakan metode Hungarian dan software POM-QM for Windows. Berdasarkan penelitian yang telah dilakukan maka didapatkan hasil berupa total waktu pengiriman produk sebelum menggunakan metode Hungarian yakni 89 menit sedangkan jika menggunakan metode Hungarian yakni 85 menit. Jadi efesiensi waktu yang didapatkan bila menggunakan metode Hungarian yaitu 4 menit. Kemudian didapatkan perbedaan penugasan dalam pengantaran produk sebelum menggunakan metode Hungarian yakni Doni mengantarkan produk dengan tujuan Cibuaya, Rahmad tujuan Cilaber, Wawan tujuan Jayakerja, Aldi tujuan Banyusari, dan Irwan tujuan Jatisari. Sedangkan bila menggunakan metode Hungarian Doni tujuan Cilaber, Rahmad tujuan Cibuaya, Wawan tujuan Banyusari, Aldi tujuan Jayakerja, dan Irwan tujuan Jatisari.
\end{abstract}

Kata kunci: penugasan, metode Hungarian, UKM (Usaha Kecil Menengah) Roti.

\begin{abstract}
UKM (Small and Medium Enterprises) Roti ZB is a company engaged in the food sector. The problem that is being faced by the company is the assignment of product delivery to consumers, each employee is facilitated by the same means of transportation but has a different delivery time. The purpose of this study is to determine the efficiency of the resulting delivery time using the Hungarian method, as well as to provide settlement arrangements for employee placement in product delivery to consumers based on the Hungarian method. This study uses the Hungarian method and POM-QM for Windows software. Based on the research that has been done, the result is that the total time of product delivery before using the Hungarian method is 89 minutes, while if using the Hungarian method is 85 minutes. So that the time efficiency obtained when using the Hungarian method is 4 minutes. Then there are differences in product delivery assignments before using the Hungarian method, namely Doni to deliver products to Cibuaya, Rahmad to Cilaber, Wawan to Jayakerja, Aldi to Banyusari, and Irwan to Jatisari. Meanwhile, if you use the Hungarian method for Doni for Cilaber, Rahmad for Cibuaya, Wawan for Banyusari, Aldi for Jayakerja, and Irwan for Jatisari.
\end{abstract}

Keywords: assignment, Hungarian method, UKM bread.

\section{Pendahuluan}

Sumber Energi Manusia yang dipunyai tiap usaha dituntut kemampuannya dalam tingkatkan efisiensi serta mengefektifkan penggunaanya. Industri kerap mengalami permasalahan berkaitan dengan alokasi maksimal mulai dari berbagai sumber energi yang produktif, lebih-lebih tenaga kerja. Perkara ini diucap kasus penugasan, yang ialah sesuatu permasalahan eksklusif dari kasus linear. Kasus penugasan berhubungan dengan kemauan industri dalam memperoleh pembagian maupun penempatan tugas yang maksimal, dalam makna bila penugasan tersebut berkaitan dengan keuntungan, maka penempatan tugas maupun penugasan tersebut harus membagikan keuntugan yang optimal (B. Prasetyo, 2020).

Salah satu dari sekian banyak prosedur pemecahan yang tersaji buat masalah-masalah penugasan ialah dengan memakai prosedur Hungarian. Prosedur Hungarian ialah prosedur yang mengubah 
baris serta kolom dalam matriks efektifitas hingga timbul suatu angka nol tunggal dalam tiap baris ataupun kolom yang bisa diseleksi dalam penempatan penugasan (Nofranti Samosir, 2019).

UKM (Usaha Kecil Menengah) Roti ZB adalah perusahaan yang bergerak pada bidang makanan, produk yang dihasilkan berupa roti $\mathrm{ZB}$ dengan tiga varian rasa yaitu coklat, kelapa, dan kacang hijau. Saat ini perusahaan sedang menghadapi masalah pada karyawan yang ditugaskan untuk mengirimkan produk, masing-masing karyawan difasilitasi alat transportasi yang sama tetapi mempunyai waktu pengantaran yang berbeda sehingga berdampak pada total efesiensi waktu pengantaran produk kepada konsumen.

Penelitian kali ini sudah pernak dilakukan oleh Eva Nurani Mukhofilah dan Nining Koesdiningsih (2018) dengan judul Analisis Penugasan Kerja Dengan Metode Hungarian Dalam Meminimumkan Biaya Produksi Pada CV. Maika Mandiri Sejahtera Cimahi. Dan Oktavianus Hia (2019) dengan judul Implementasi Metode Hungarian Dalam Penugasan Karyawan (Studi Kasus: PT. Jefrindo Consultant).

Tujuan yang hendak dicapai dalam riset ini ialah Mengetahui efisiensi waktu pengiriman yang dihasilkan dengan memakai prosedur Hungarian, serta membagikan penyelesaian pengaturan penempatan karyawan dalam pengantaran produk kepada konsumen berlandaskan prosedur Hungarian.

\section{Bahan dan Metode}

Tipe riset yang digunakan merupakan riset aksi (action research). Riset aksi ialah riset yang dicoba buat memperoleh temuan-temuan instan buat keperluan pengambilan keputusan guna meningkatkan keahlian baru maupun pendekatan baru (Sinulingga, 2011). Penelitian ini menggunakan data primer, didapat melalui pengamatan langsung dan mewawancarai pemilik dan karyawan pabrik roti mengenai waktu yang ditempuh dalam pengiriman produk kepada konsumen. Serta data sekunder, didapat melalui arsip perusahaan yang berhubungan dengan waktu pengiriman produk. Alur pengolahan data riset ini dijelaskan pada Gambar 1 .

Berikut penjelasan dari masing-masing metode yang dipakai dalam penelitian ini.

\section{Metode Hungarian}

Cara ini ditemui oleh Harold Kuhn pada tahun 1955 serta setelah itu diteliti oleh James Munkres pada tahun 1957, sebab itu prosedur Hungarian biasa disebut pula metode Kuhn-Munkres. Untuk bisa mengaplikasikan Prosedur Hungarian, jumlah pekerja yang ditugaskan mesti sama dengan jumlah tujuan yang hendak dituntaskan (Dwi Harini, 2017).

Langkah penyelesaian metode penugasan mengenakan prosedur Hungarian, yaitu:
1. Memahami serta menyederhanakan permasalahan atau data yang sudah didapat kedalam wujud matriks penugasan,

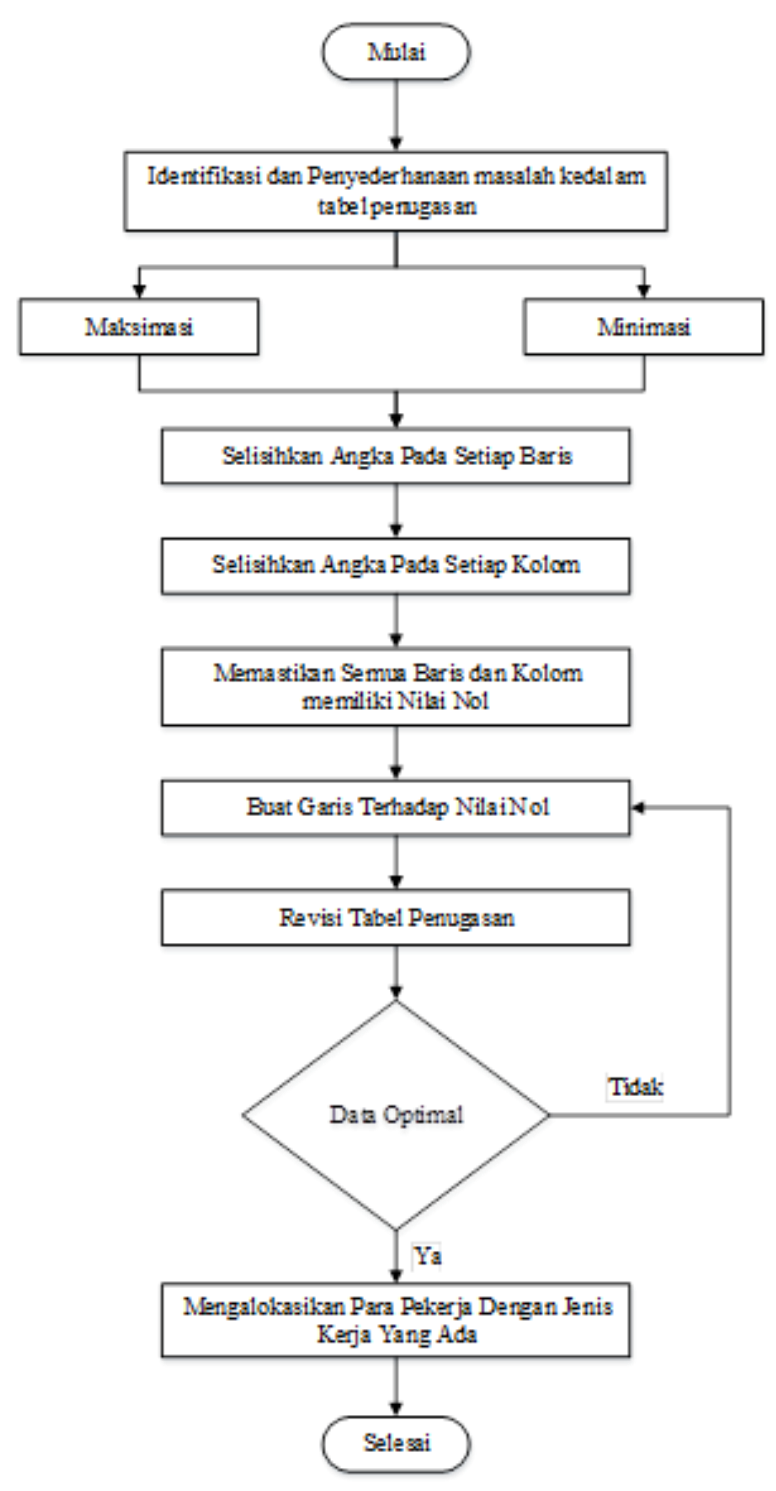

Gambar 1. Flowchart Alur Pengolahan Data

2. Menentukan angka minimum pada setiap baris, kemudian mengurangi angka yang ada pada setiap baris dengan angka minimum.

3. Menentukan angka minimum pada setiap kolom, kemudian mengurangi angka yang ada pada setiap kolom dengan angka minimum.

4. Membuat garis pada baris maupun kolom yang memiliki angka nol melalui teknik memilah baris maupun kolom yang mempunyai nol paling banyak terlebih dahulu. Apabila total garis sama dengan banyaknya baris maupun kolom berarti tabel sudah optimal. Apabila tidak, maka teruskan ke langkah berikutnya. 
5. Menentukan nilai minimum dari angka yang belum tertutup oleh garis, selanjutnya mengurangi seluruh angka yang belum tertutup garis dengan nilai minimum, serta menjumlahkan angka yang tertutup oleh dua garis dengan nilai minimum, sedangkan angka yang tertutup oleh satu garis nilainya tetap.

6. Ketika matriks sudah optimal, Langkah terakhir menentukan penugasan dimulai dari jumlah baris yang paling sedikit memiliki angka 0 .

\section{POM-QM For Windows}

POM-QM for Windows ialah fitur yang dibuat menyertai buku-buku bacaan seputar manajemen operasi yang diterbitkan oleh Prentice-Hall's. aplikasi ini dikembangkan oleh Howard J. Weiss tahun 1996 buat memudahkan perhitungan dalam bisnis yang bersifat kuantitatif, aplikasi ini dikembangkan hanya untuk mengeloka perhitungannya saja, jadi pengguna disarankan bisa menginterpretasikan permasalahan serta teori linear programming. Adapun Langkahlangkah menggunakan software ini dalam kasus penugasan sebagai berikut:

1. Buka aplikasi POM-QM for Windows.

2. Klik module kemudian pilih assignment.

3. Klik file kemudian pilih new.

4. Isi tabel yang muncul secara otomatis, mulai dari title, number of jobs, dan number of machines. Kemudian pada kolom objective klik minimize setelah itu klik OK.

5. Input data pada tabel yang disediakan, kemudian klik solve.

\section{Hasil dan Pembahasan}

Diketahui jumlah karyawan yang bertugas mengantarkan produk kepada konsumen berjumlah 5 orang serta tujuan juga 5 lokasi, setiap pekerja memiliki waktu pengiriman produk tidak sama, sehingga diperlukan analisis untuk menugaskan karyawan tersebut agar mendapatkan waktu pengantaran yang optimal. Berikut adalah data penugasan dan waktu pengantaran produk sebelum menerapkan metode Hungarian.

Tabel 1. Hasil Penugasan dan Waktu Pengantaran Produk Sebelum Menggunakan Metode Hungarian

\begin{tabular}{|c|c|c|}
\hline Karyawan & Tujuan & Waktu \\
\hline Doni & Cibuaya & 14 \\
\hline Rahmad & Cilaber & 18 \\
\hline Wawan & Jayakerja & 18 \\
\hline Aldi & Banyusari & 20 \\
\hline Irwan & Jatisari & 19 \\
\hline \multicolumn{2}{|c|}{ Tota } & 89 \\
\hline
\end{tabular}

Berikut Langkah-langkah untuk menyelesaikan masalah penugasan menggunakan metode Hungarian.

\section{Langkah 1}

Data yang sudah didapatkan pada saat observasi lapangan, diubah kedalam bentuk tabel yang lebih sederhana. Hasil dari Langkah 1 dijelaskan pada Tabel2.

Tabel 2. Hasil Waktu Pengantaran Produk Data Waktu Pengantaran Produk (Menit)

\begin{tabular}{lccccc}
\hline \multirow{2}{*}{ Karyawan } & \multicolumn{5}{c}{ Tujuan } \\
\cline { 2 - 6 } & $\begin{array}{c}\text { Bany } \\
\text { usari }\end{array}$ & $\begin{array}{c}\text { Cibu } \\
\text { aya }\end{array}$ & $\begin{array}{c}\text { Jatis } \\
\text { ari }\end{array}$ & $\begin{array}{c}\text { Cila } \\
\text { ber }\end{array}$ & $\begin{array}{c}\text { Jayak } \\
\text { erja }\end{array}$ \\
\hline Doni & 20 & 14 & 24 & 16 & 22 \\
\hline Rahmad & 22 & 14 & 20 & 18 & 23 \\
\hline Wawan & 18 & 23 & 21 & 20 & 18 \\
\hline Aldi & 20 & 23 & 25 & 24 & 18 \\
\hline Irwan & 20 & 22 & 19 & 18 & 20 \\
\hline
\end{tabular}

\section{Langkah 2}

Menetapkan nilai minimum pada setiap baris. Hasil dari Langkah 2 dijelaskan pada Tabel 3.

Tabel 3. Nilai Minimum Setiap Baris

\begin{tabular}{cc}
\hline $\begin{array}{c}\text { Nomer } \\
\text { Baris }\end{array}$ & $\begin{array}{c}\text { Nilai } \\
\text { Minimum }\end{array}$ \\
\hline 1 & 14 \\
\hline 2 & 14 \\
\hline 3 & 18 \\
\hline 4 & 18 \\
\hline 5 & 18 \\
\hline
\end{tabular}

\section{Langkah 3}

Kurangi entri yang ada pada setiap baris dengan nilai minimum, contohnya sebagai berikut: Baris 1, 2014, 14-14, 24-14, 16-14, 22-14. Hasil dari Langkah 3 dijelaskan pada Tabel 4 .

Tabel 4. Hasil Pengolahan Data Data Waktu Pengantaran Produk (Menit)

\begin{tabular}{lccccc}
\hline \multirow{2}{*}{ Karyawan } & \multicolumn{5}{c}{ Tujuan } \\
\cline { 2 - 6 } & $\begin{array}{c}\text { Bany } \\
\text { usari }\end{array}$ & $\begin{array}{c}\text { Cibu } \\
\text { aya }\end{array}$ & $\begin{array}{c}\text { Jatis } \\
\text { ari }\end{array}$ & $\begin{array}{c}\text { Cila } \\
\text { ber }\end{array}$ & $\begin{array}{c}\text { Jayak } \\
\text { erja }\end{array}$ \\
\hline Doni & 6 & 0 & 10 & 2 & 8 \\
\hline Rahmad & 8 & 0 & 6 & 4 & 9 \\
\hline Wawan & 0 & 5 & 3 & 2 & 0 \\
\hline Aldi & 2 & 5 & 7 & 6 & 0 \\
\hline Irwan & 2 & 4 & 1 & 0 & 3 \\
\hline
\end{tabular}

\section{Langkah 4}

Setelah mendapatkan hasil dari Langkah 3, kemudian tentukan nilai minimum pada setiap kolom. Hasil dari Langkah 4 dijelaskan pada Tabel 5. 
Jurnal Pendidikan dan Aplikasi Industri (UNISTEK)

Vol. 8 No.1 Februari 2021

p- ISSN : 0126 - 4036

e- ISSN : $2716-0416$

Tabel 5. Nilai Minimum Setiap Kolom

\begin{tabular}{cccccc}
\hline $\begin{array}{c}\text { Nomer } \\
\text { Kolom }\end{array}$ & 1 & 2 & 3 & 4 & 5 \\
\hline $\begin{array}{c}\text { Nilai } \\
\text { Minimum }\end{array}$ & 0 & 0 & 1 & 0 & 0 \\
\hline
\end{tabular}

\section{Langkah 5}

Kurangi entri yang ada pada setiap kolom dengan nilai minimum, contohnya sebagai berikut: Kolom 1, 6$0,8-0,0-0,2,0,2-0$. Hasil dari Langkah 5 dijelaskan pada Tabel 6.

Tabel 6. Pengolahan Data

\begin{tabular}{lccccc}
\hline \multicolumn{5}{c}{ Data Waktu Pengantaran Produk (Menit) } \\
\hline \multirow{3}{*}{ Karyawan } & \multicolumn{5}{c}{ Tujuan } \\
\cline { 2 - 6 } & $\begin{array}{c}\text { Bany } \\
\text { usari }\end{array}$ & $\begin{array}{c}\text { Cibu } \\
\text { aya }\end{array}$ & $\begin{array}{c}\text { Jatis } \\
\text { ari }\end{array}$ & $\begin{array}{c}\text { Cila } \\
\text { ber }\end{array}$ & $\begin{array}{c}\text { Jayak } \\
\text { erja }\end{array}$ \\
\hline Doni & 6 & 0 & 9 & 2 & 8 \\
\hline Rahmad & 8 & 0 & 5 & 4 & 9 \\
\hline Wawan & 0 & 5 & 2 & 2 & 0 \\
\hline Aldi & 2 & 5 & 6 & 6 & 0 \\
\hline Irwan & 2 & 4 & 0 & 0 & 3 \\
\hline
\end{tabular}

\section{Langkah 6}

Memastikan apakah matriks sudah optimal atau belum, dengan cara menutupi semua entri 0 menggunakan garis, dimulai dari yang memiliki entri 0 terbanyak baik pada baris maupun kolom. Hasil dari Langkah 6 dijelaskan pada Tabel 7.

Tabel 7. Pengolahan Data

\begin{tabular}{lccccc}
\hline \multicolumn{5}{c}{ Tabel 7. Pengolahan Data } \\
\hline \multirow{3}{*}{ Karyawa Waktu Pengantaran Produk (Menit) } \\
\cline { 2 - 6 } & $\begin{array}{c}5 \\
\text { Bany } \\
\text { usari }\end{array}$ & $\begin{array}{c}\text { Cibuan } \\
\text { aya }\end{array}$ & $\begin{array}{c}\text { Jatis } \\
\text { ari }\end{array}$ & $\begin{array}{c}\text { Cila } \\
\text { ber }\end{array}$ & $\begin{array}{c}\text { Jayak } \\
\text { erja }\end{array}$ \\
\hline Doni & $\$$ & 0 & 9 & 2 & $\$$ \\
\hline Rahmad & $\$$ & $\phi$ & 5 & 4 & $\$$ \\
\hline Wawan & 0 & $\$$ & 2 & 2 & 0 \\
\hline Aldi & & $\$$ & 6 & 6 & 0 \\
\hline Irwan & 2 & 4 & 0 & 0 & 3 \\
\hline
\end{tabular}

Matriks dapat dikatakan optimal bila kuantitas garis sama dengan kuantitas baris ataupun kolom, dilihat pada Tabel 7 jumlah garisnya 4 sedangkan jumlah baris ataupun kolom 5 artinya matriks belum optimal.

\section{Langkah 7}

Carilah nilai minimal pada entri yang belum tertutup oleh garis, nilai minimum yang didapat adalah 2. Dalam Langkah ini terdapat 3 ketentuan diantaranya, yaitu:

1. Semua entri yang tidak tertutup oleh garis dikurangi dengan nilai minimum.
2. Semua entri yang tertutup oleh satu garis nilainya tetap atau tidak berubah.

3. Semua entri yang tertutup oleh dua garis dijumlahkan dengan nilai minimum.

Contoh pengolahan data pada Langkah ini sebagai berikut:

1. Entri yang tidak tertutup oleh garis pada kolom 3 ialah 9, 5, 2, 6. Maka didapatkan 9-2, 5-2, 2-2, 62.

2. entri yang tertutup satu garis pada kolom 1 ialah $6,8,0,2$. Maka nilai tersebut pada matriks tidak berubah.

3. Entri yang tertutup oleh dua garis pada kolom 1 ialah 2. Maka didaptkan $2+2$. Hasil dari Langkah 7 dijelaskan pada Tabel 8.

Tabel 8. Pengolahan Data Data Waktu Pengantaran Produk (Menit)

\begin{tabular}{lccccc}
\hline \multirow{2}{*}{ Karyawan } & \multicolumn{5}{c}{ Tujuan } \\
\cline { 2 - 6 } & $\begin{array}{c}\text { Bany } \\
\text { usari }\end{array}$ & $\begin{array}{c}\text { Cibu } \\
\text { aya }\end{array}$ & $\begin{array}{c}\text { Jatis } \\
\text { ari }\end{array}$ & $\begin{array}{c}\text { Cila } \\
\text { ber }\end{array}$ & $\begin{array}{c}\text { Jayak } \\
\text { erja }\end{array}$ \\
\hline Doni & 6 & 0 & 7 & 0 & 8 \\
\hline Rahmad & 8 & 0 & 3 & 2 & 9 \\
\hline Wawan & 0 & 5 & 0 & 0 & 0 \\
\hline Aldi & 2 & 5 & 6 & 6 & 0 \\
\hline Irwan & 4 & 6 & 0 & 0 & 5 \\
\hline
\end{tabular}

\section{Langkah 8}

Memastikan kembali apakah matriks sudah optimal atau belum, dengan cara menutupi semua entri 0 menggunakan garis, dimulai dari yang memiliki entri 0 terbanyak baik pada baris maupun kolom. Hasil dari Langkah 8 dijelaskan pada Tabel 9.

Tabel 9. Pengolahan Data Data Waktu Pengantaran Produk (Menit)

\begin{tabular}{lccccc}
\hline \multirow{2}{*}{ Karyawan } & \multicolumn{5}{c}{ Tujuan } \\
\cline { 2 - 6 } & $\begin{array}{c}\text { Bany } \\
\text { usari }\end{array}$ & $\begin{array}{c}\text { Cibu } \\
\text { aya }\end{array}$ & $\begin{array}{c}\text { Jatis } \\
\text { ari }\end{array}$ & $\begin{array}{c}\text { Cila } \\
\text { ber }\end{array}$ & $\begin{array}{c}\text { Jayak } \\
\text { erja }\end{array}$ \\
\hline Doni & 6 & & 7 & 0 & $\$$ \\
\hline Rahmad & 8 & & 3 & 2 & $\$$ \\
\hline Wawan & 0 & & 0 & 0 & $\$$ \\
\hline Aldi & 2 & $\$$ & 6 & 6 & $\$$ \\
\hline Irwan & 4 & & 0 & 0 & 5 \\
\hline
\end{tabular}

Matriks dapat dikatakan optimal bila kuantitas garis sama dengan kuantitas baris ataupun kolom, dilihat pada Tabel 9 jumlah garisnya 5 sedangkan jumlah baris ataupun kolom 5 artinya matriks sudah optimal.

\section{Langkah 9}

Karena matriks sudah optimal, Langkah terakhir adalah penentuan penugasan, dimulai dari jumlah baris yang paling sedikit memiliki nilai 0 . Hasil dari Langkah 9 dijelaskan pada Tabel 10 dan 11. 
Jurnal Pendidikan dan Aplikasi Industri (UNISTEK)

Vol. 8 No.1 Februari 2021

p- ISSN : 0126 - 4036

e- ISSN : $2716-0416$

Tabel 10. Pengolahan Data Data Waktu Pengantaran Produk (Menit)

\begin{tabular}{lccccc}
\hline \multirow{2}{*}{ Karyawan } & \multicolumn{5}{c}{ Tujuan } \\
\cline { 2 - 6 } & $\begin{array}{c}\text { Bany } \\
\text { usari }\end{array}$ & $\begin{array}{c}\text { Cibu } \\
\text { aya }\end{array}$ & $\begin{array}{c}\text { Jatis } \\
\text { ari }\end{array}$ & $\begin{array}{c}\text { Cila } \\
\text { ber }\end{array}$ & $\begin{array}{c}\text { Jayak } \\
\text { erja }\end{array}$ \\
\hline Doni & 6 & 0 & 7 & 0 & 8 \\
\hline Rahmad & 8 & 0 & 3 & 2 & 9 \\
\hline Wawan & 0 & 5 & 0 & 0 & 0 \\
\hline Aldi & 2 & 5 & 6 & 6 & 0 \\
\hline Irwan & 4 & 6 & 0 & 0 & 5 \\
\hline
\end{tabular}

Tabel 11. Penugasan Karyawan Menggunakan Metode Hungarian

\begin{tabular}{ccc}
\hline Karyawan & Tujuan & Waktu \\
\hline Doni & Cilaber & 16 \\
\hline Rahmad & Cibuaya & 14 \\
\hline Wawan & Banyusari & 18 \\
\hline Aldi & Jayakerja & 18 \\
\hline Irwan & Jatisari & 19 \\
\hline \multicolumn{2}{c}{ Total } & 85
\end{tabular}

Sementara itu Adapun Langkah-langkah perhitungan menggunakan tools POM-QM For Windows, yaitut:

1. Buka tools POM-QM for windows.

2. Klik module kemudian pilih assignment.

3. Klik file kemudian pilih new.

4. Isi tabel yang keluar secara otomatis, mulai dari title, number of jobs, dan number of machines, kemudian pada kolom objective klik minimize setelah itu klik OK.

5. Input data pada tabel yang disediakan, lalu klik solve.

Hasil perhitungan menggunakan POM-QM For Windows dijelaskan pada Gambar 2 dan 3.

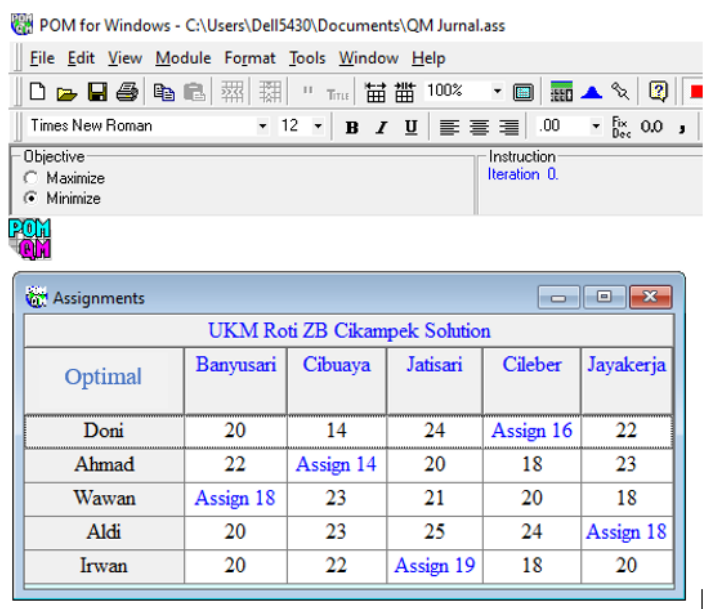

Gambar 2. Hasil Perhitungan Penugasan Menggunakan POM-QM For Windows.
Dari hasil perhitungan yang sudah dilakukan baik manual ataupun menggunakan software didapatkan hasil yang sama dengan alokasi penugasan untuk masing-masing karyawan yaitu, Doni ditugaskan mengirimkan produk ke Cileber, Ahmad ke Cibuaya, Wawan ke Banyusari, Aldi ke Jayakerja, dan Irwan ke Jatisari. Dengan total pengiriman waktu optimal yaitu 85 menit.

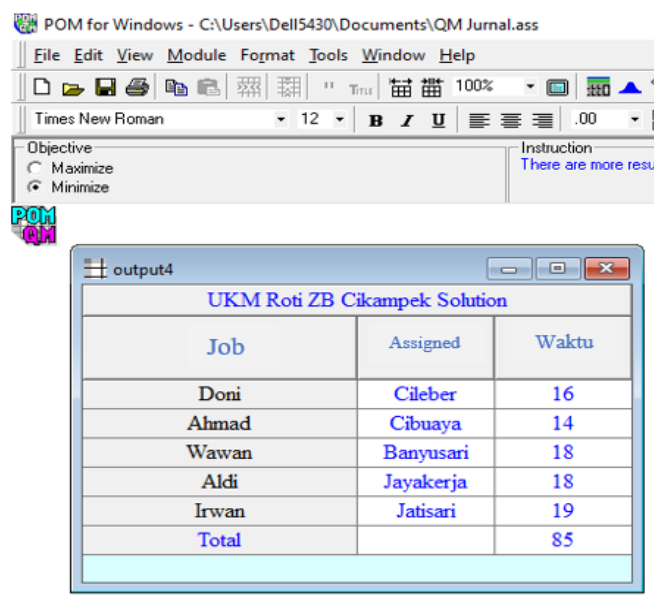

Gambar 3. Hasil Perhitungan Penugasan Menggunakan POM-QM For Windows

\section{Kesimpulan}

Dari hasil analisis yang sudah dilakukan tentang penugasan karyawan menggunakan metode Hungarian pada UKM Roti ZB Cikampek, didapatkan beberapa kesimpulan diantaranya yaitu:

1. Total waktu pengiriman produk sebelum menerapkan metode Hungarian ialah 89 menit atau 5340 detik, sedangkan total waktu pengiriman produk jika menggunakan metode Hungarian adalah 85 menit atau 5100 detik.

2. Didapatkan perbedaan pengaturan penugasan dalam mengirimkan produk sebelum menggunakan metode Hungarian dan jika menggunakan metode Hungarian, Adapun pengaturan penugasannya dapat dilihat pada Tabel 12.

Tabel 12. Penugasan Sebelum dan Sesudah Menggunakan Metode Hungarian

\begin{tabular}{llll}
\hline \multicolumn{2}{c}{ Sebelum } & \multicolumn{2}{c}{ Sesudah } \\
\hline Karyawan & Tujuan & Karyawan & Tujuan \\
\hline Doni & Cibuaya & Doni & Cilaber \\
\hline Rahmad & Cilaber & Rahmad & Cibuaya \\
\hline Wawan & Jayakerja & Wawan & Banyusari \\
\hline Aldi & Banyusari & Aldi & Jayakerja \\
\hline Irwan & Jatisari & Irwan & Jatisari \\
\hline
\end{tabular}


Jurnal Pendidikan dan Aplikasi Industri (UNISTEK)

Vol. 8 No.1 Februari 2021

p- ISSN : 0126 - 4036

e- ISSN : $2716-0416$

Dengan demikian bahwa alokasi penugasan menggunakan metode Hungarian dapat memberikan efesiensi waktu sebesar 4 menit atau 240 detik.

\section{Daftar Pustaka}

B. Prasetyo, A. (2020). Penyelesaian Masalah Penugasan Pada Drafter Menggunakan Metode Hungarian dan Aplikasi POM-QM. Bulletin of Applied Industrial Engineering Theory, 21-27.

Dwi Harini. (2017). Optimasi Penugasan Menggunakan Metode Hungarian Pada CV. L\&J Express Malang (Kasus Minimasi). Jurnal Intensif, 68-74.

Erlinda Rahmawati, N. F. (2015). Optimasi Masalah Penugasan Menggunakan Metode Hungarian (Studi Kasus Pada PT Pos Indonesia (Persero) Pontianak). Bimaster, 363-370.

Eva Nurani Mukhofilah, N. (2018). Analisis Penugasan Kerja Dengan Metode Hungarian Dalam Meminimumkan Biaya Produksi Pada CV. Maika Mandiri Sejahtera Cimahi. Prosiding Manajemen, 87-92.

Herlawati. (2017). Algoritma Hungarian Dalam Menentukan Pembagian Tugas Sebagai Manajemen Jurnal Pada Open journal Sistem (OJS). Information System For Educator and Professionals, 83-94.

Idris Gautama So, H. R. (2013). Penerapan Metode Hungarian Pada Perusahaan Jasa (Kasus Minimum). Binus Business Review, 812-820.

Marline Paendong, J. (2011). Optimasi Pembagian Tugas Karyawan Menggunakan Metode Hungarian. Jurnal Ilmiah Sains, 109-115.

Nofranti Samosir. (2019). Penerapan Metode Hungarian Dalam Optimasi Biaya Marketing Pada PT. Jovi Karunia Jaya. Jurnal Riset Komputer (JURIKOM), 416-420.

Oktavianus Hia. (2019). Implementasi Metode Hungarian Dalam Penugasan Karyawan (Studi Kasus: PT. Jefrindo Consultant). Jurnal Riset Komputer (JURIKOM), 85-92.

S. Mardiani, F. C. (2020). Penerapan Metode Hungarian Dalam Optimasi Penugasan Karyawan CV. Paksi Teladan. Bulletin of Applied Industrial Engineering Theory, 1-6.

Sinulingga, S. (2011). Metode Penelitian. Medan: USU Press.

Sri Basriati, A. (2017). Penyelesaian Masalah Penugasan Menggunakan Metode Hungarian dan Pinalti (Studi Kasus: CV. Surya Pelangi). Jurnal Sains Matematika dan Statistika, 7581. 